\title{
Endoscopic vacuum sponge therapy for an infant with an esophageal leak
}

\author{
Jose Carlos Fraga, MD, MSc, PhD, FAAP, ${ }^{a}$ Daltro L. Nunes, MD, ${ }^{\mathrm{b}}$ Cinara Andreolio, MD, ${ }^{\mathrm{c}}$ \\ Julia Ferreira, MD, ${ }^{\mathrm{d}}$ Felipe Holanda, MD, ${ }^{\mathrm{d}}$ Paola S. Isolan, MD, PhD, FAAP, ${ }^{\mathrm{d}}$ and Russell Jennings, MD, \\ Porto Alegre, Brazil, and Boston, Mass
}

\footnotetext{
From the ${ }^{a}$ Pediatric Thoracic Surgery Unit, Pediatric Surgery Service, and ${ }^{\mathrm{d}}$ Pediatric Surgery Service, Department of Surgery, Hospital de Clinicas of Porto Alegre, School of Medicine, Federal University of Rio Grande do Sul, Porto Alegre, Brazil; ${ }^{b}$ Pediatric Gastroenterology Unit and ${ }^{c}$ Pediatric Emergency and Intensive Care Unit, Service of Pediatrics, Hospital de Clinicas of Porto Alegre, Porto Alegre, Brazil; and ${ }^{\mathrm{e}}$ Esophageal and Airway Treatment Center, Department of Surgery, Boston Children's Hospital, Harvard Medical School, Boston, Mass.

Disclosures: Authors have nothing to disclose with regard to commercial support.

Received for publication Feb 18, 2018; revisions received April 9, 2018; accepted for publication April 11, 2018; available ahead of print May 11, 2018.

Address for reprints: Jose Carlos Fraga, MD, MSc, PhD, FAAP, Rua Ramiro Barcelos 2350, Sala 600 Bairro Santa Cecilia, CEP 90035-903, Porto Alegre, RS, Brazil (E-mail: fraga.jcs@ gmail.com).

J Thorac Cardiovasc Surg 2018; 156:e193-5

$0022-5223 / \$ 36.00$

Copyright (C) 2018 by The American Association for Thoracic Surgery

https://doi.org/10.1016/j.jtcvs.2018.04.061
}

Video clip is available online.

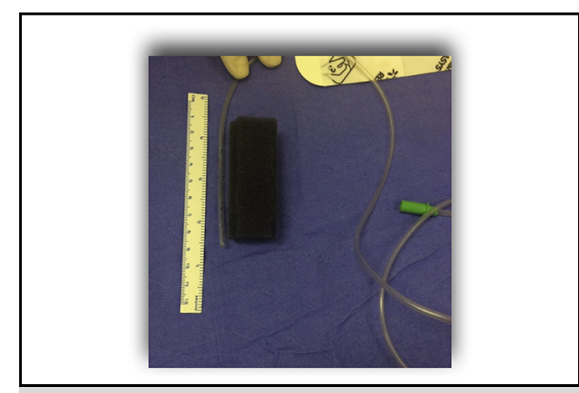

Esophageal vacuum sponge prepared in a cylinder resembling the esophageal lumen.

\section{Central Message}

Endoscopic vacuum treatment effectively treated an esophageal leak in an infant. This therapy should be considered as a treatment option in children with esophageal perforation.

See Editorial Commentary page e197.
In recent years, endoscopic vacuum-assisted closure (E-VAC) treatment has been successfully used as a novel endoscopic treatment option for esophageal leaks in adults ${ }^{1,2}$; however, E-VAC treatment has not been described in children and infants. We report the first case of an infant who was successfully treated by E-VAC for esophageal iatrogenic perforation after thoracoscopic lobectomy.

\section{CASE DESCRIPTION}

An 8-month-old boy showed distal esophageal perforation (Figure 1) after video-assisted thoracoscopic lobectomy for right lower lobe congenital malformation. The child underwent immediate thoracotomy, and a $1-\mathrm{cm}$ burn area was observed in the lower esophagus, with punctate perforation in its central portion. Local débridement was performed, with suture repair of the esophageal opening with 4-0 and 5-0 polydioxanone suture. Patient recovered in the pediatric intensive care unit with chest tube placement, nothing by mouth, total parenteral nutrition, intravenous antibiotic, and intravenous omeprazole for gastric $\mathrm{pH}$ control. Surgery's record review showed that esophageal damage occurred during pulmonary ligament division. The camera view was not over the structure, but rather was positioned laterally, and this inclined position caused viewing difficulties during pulmonary ligament release. The LigaSure (Medtronic, Inc, Minneapolis, Minn) forceps used in the procedure was likely too close to the esophagus and caused a cautery

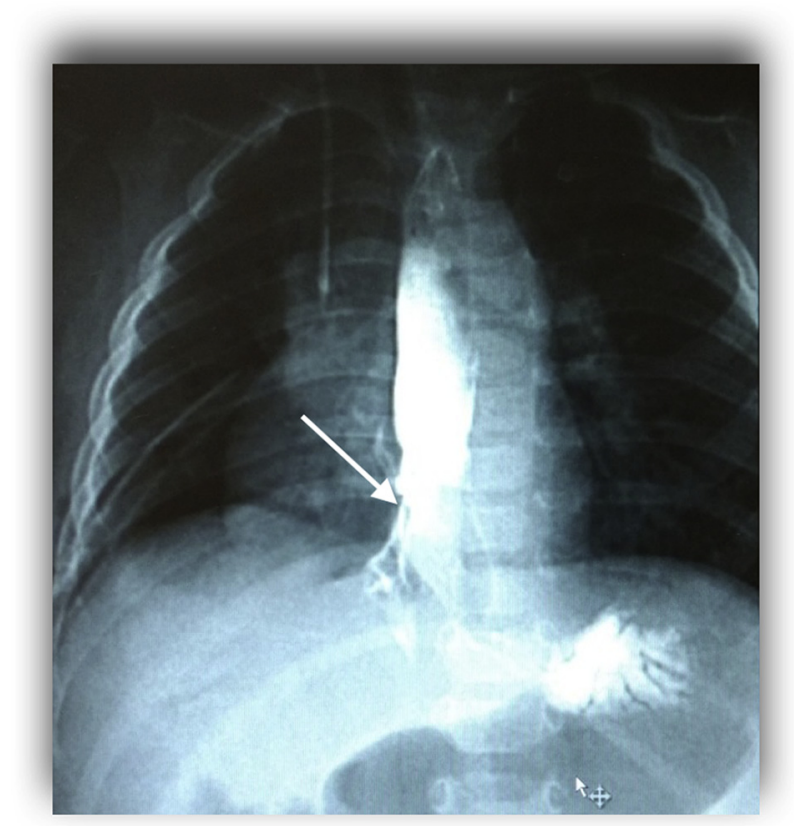

FIGURE 1. Posthoracoscopy esophageal contrast study showing perforation at the distal third of the esophagus (arrow). 


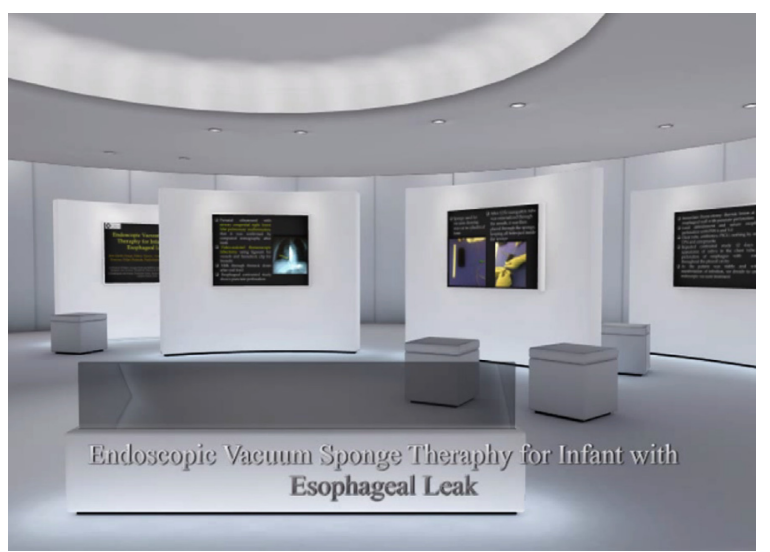

VIDEO 1. Case report and endoscopic vacuum-assisted closure (E-VAC) technique details. PDS, Polydioxanone suture; $P I C U$, pediatric intensive care unit. Video available at: https://www.jtcvs.org/article/ S0022-5223(18)31048-1/fulltext.

injury to the esophagus, which later developed into an esophageal leak.

The appearance of saliva in the chest tube 12 days after thoracotomy prompted the performance of a new esophagogram, which showed a free perforation of the esophagus with contrast throughout the pleural cavity. Because surgery had already failed, we decided on the use of the E-VAC system.

A portion of a sponge used in vacuum dressing for surgical incisions (RENASYS Foam Dressing Kit;
Smith \& Nephew Medical Ltd, London, United Kingdom) was cut into a cylinder, with a caliber resembling the esophageal lumen. A $12 \mathrm{~F}$ nasogastric tube was passed through the child's right nostril and then externalized through his mouth. The tube was then placed through the sponge, keeping all holes just inside the sponge. Nonabsorbable sutures were used to attach a tube to the sponge. The sponge was passed into the pharynx by laryngoscopy and gently manipulated to the distal esophagus with fluoroscopic assistance and under endoscopic vision with esophageal gastroduodenoscopy (GIF Q 180; Olympus America Inc, Center Valley, Pa), placing the esophageal injury into contact with the middle portion of the sponge. A chest radiograph was then obtained, confirming that the sponge was in the desired position. The nasogastric tube was fixed in position at the nostril with Micropore surgical tape (3M, St Paul, Minn), and negative continuous suction of $120 \mathrm{~mm} \mathrm{Hg}$ was applied on the nasogastric tube with a vacuum pump (RENASYS Negative Pressure Wound Therapy; Smith \& Nephew). After negative pressure had been achieved in the nasogastric tube, drainage of secretions from the chest drain gradually decreased. Repeated esophagoscopy and contrast study performed 4 days after starting the vacuum treatment showed a large inflammatory process in the distal esophagus, with no evidence of esophageal leak. The sponge was removed, and a siliconized nasoenteric tube was placed under endoscopic vision. The patient continued

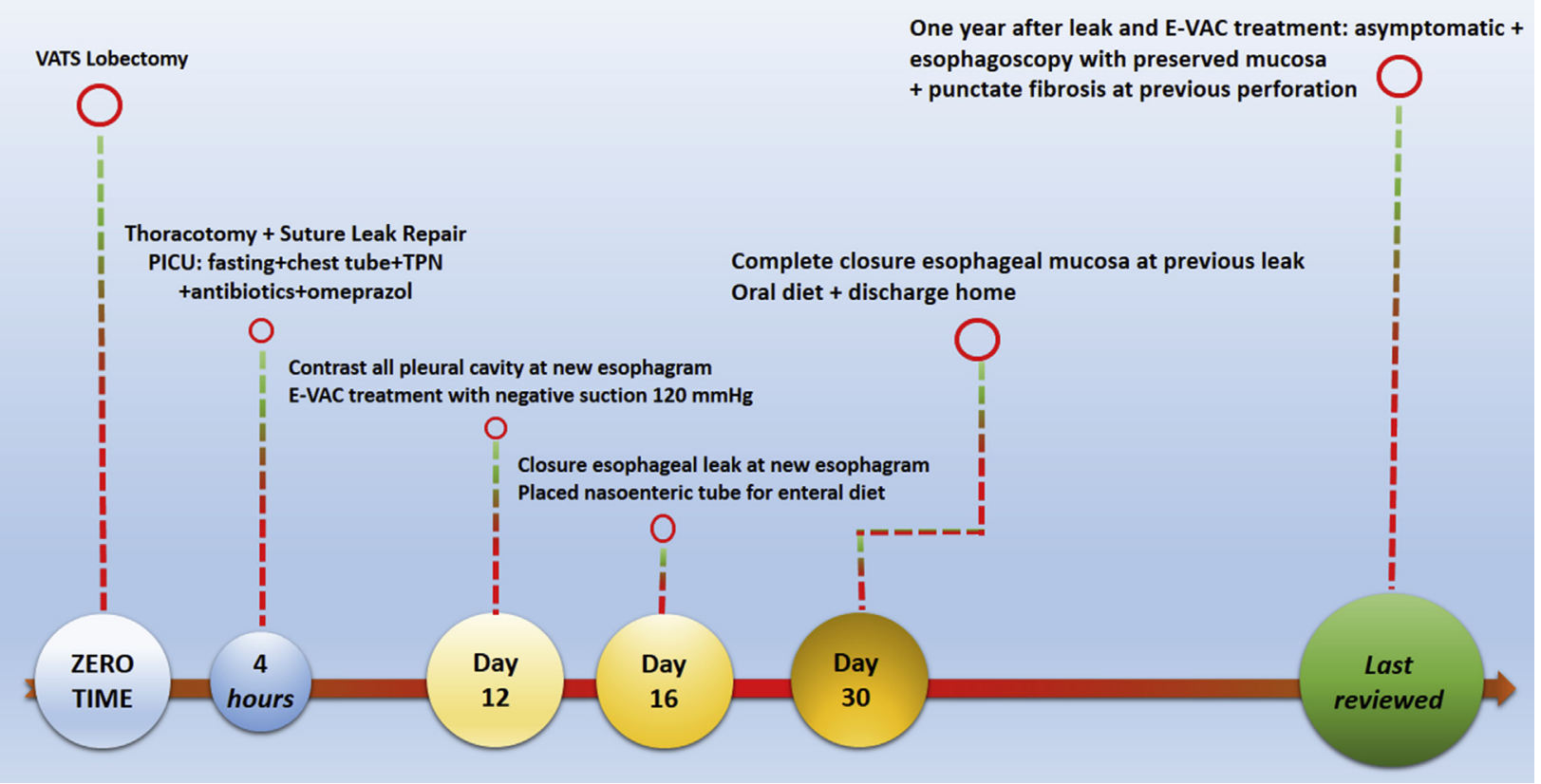

FIGURE 2. Timeline showing need for the various interventions. VATS, Video-assisted thoracoscopic surgery; E-VAC, endoscopic vacuum-assisted closure; $P I C U$, pediatric intensive care unit; $T P N$, total parenteral nutrition. 
to receive nothing by mouth but started with an enteral diet. The parenteral nutrition and thoracic drainage were discontinued. Fourteen days after nasoenteric catheter placement, repeated endoscopy showed complete closure of the esophageal mucosa in the region of previous perforation. The nasogastric tube was removed, and the child was discharged on an oral diet (Video 1). Twelve months after the esophageal perforation, the patient was free of symptoms, and endoscopy showed that the esophagus had preserved mucosa, with a minimal area of nonobstructive fibrosis in the region of previous perforation (Figure 2).

\section{DISCUSSION}

Historically, esophageal leaks have been surgically treated, but current treatment options also include endoscopic management of esophageal perforation in patients without septicemia who are in stable condition. ${ }^{3}$ E-VAC works with intraesophageal application of negative pressure at the defect zone through an electronically controlled vacuum device along a polyurethane sponge drainage system. The sponge placement allows coaptation within the esophagus through suction, requiring no other type of seal. Continuous negative suction and drainage decrease bacterial contamination, secretion accumulation, and local edema, as well as allowing the cavity to collapse around the sponge. At the same time, perfusion and development of granulation tissue are promoted.

E-VAC treatment should be attempted by an interdisciplinary team in a center with expertise in interventional endoscopy and intensive care medicine. ${ }^{4}$ With this care, the effectiveness of E-VAC in adults with esophageal perforation varies from $83 \%$ to $100 \%$, with an overall success rate of $90 \% .^{5}$ Although E-VAC looks like a promising modality for the treatment of esophageal leaks in infants, further investigation is necessary to confirm whether it could really be an option in the treatment of children with esophageal perforation.

\section{References}

1. Mennigen R, Senninger N, Laukoetter MG. Novel treatment options for perforations of the upper gastrointestinal tract: endoscopic vacuum therapy and over-the-scope clips. World J Gastroenterol. 2014;20:7767-76.

2. Yon HC, Kwon SH. Endoscopic vacuum-assisted closure (E-VAC) treatment in a patient with delayed anastomotic perforation following a perforated gastric conduit repair after an Ivor-Lewis esophagectomy. Ann Thorac Cardiovasc Surg. 2016;22:363-6.

3. Leo MD, Maselli R, Ferrara EC, Poliani L, Al Awadhi S, Repici A. Endoscopic management of benign esophageal ruptures and leaks. Curr Treat Options Gastroenterol. 2017;15:268-84.

4. Möschler I, Nies C, Mueller MK. Endoscopic vacuum therapy for esophageal perforations and leakages. Endosc Int Open. 2015;3:E554-8.

5. Kuehn F, Loske G, Schiffmann L, Gock M, Klar E. Endoscopic vacuum therapy for defects of the upper gastrointestinal tract. Surg Endosc. 2017; 31:3449-58. 